\title{
Toxicological Effects Induced by Chlorpyrifos Administration on Thyroid and Suprarenal Glands in Adult Male Albino Rats
}

\author{
Melad Gad Paules, Jaklin Fekri Zaher, Esam Mahmoud Hafez ${ }^{1}$ and Nashoa \\ Fathy El-Tahawy²
}

\footnotetext{
${ }^{1}$ Department of Forensic Medicine and Clinical Toxicology

${ }^{2}$ Histology Department
}

Faculty of Medicine, Minia University, Minia, Egypt.

\begin{abstract}
Chlorpyrifos (CPF) is a broad spectrum organophosphorus (OP) insecticide used in the control of a wide variety of insects. Its wide use in agriculture raises a growing public concern about the accumulation of these insecticides in food products and water supplies. The aim of this work was to evaluate the toxicological effect of CPF on thyroid and suprarenal glands. Twenty adult male albino rats were used in this work and divided into two groups: control (group I) and CPF-treated (group II). The treated group received CPF daily in a dose of $5.4 \mathrm{mg} / \mathrm{kg}$ orally for 28 days. Serum T3, T4, TSH, corticosterone and malondialdehyde (MDA) were determined. The thyroid and suprarenal glands were evaluated for oxidative stress and microscopically. Results showed that CPF induced a significant decrease of serum T3 and T4 and a significant increase of serum TSH. Serum corticosterone was increased but statistically insignificant. Serum and tissues MDA were significantly increased. Histological examination of thyroid gland revealed that most follicles appeared degenerated with empty lumen due to decrease colloid, obvious exfoliation of the follicular epithelial cells and vascular congestion. Adrenals showed increased vacuolations of zona granulosa cells. Thus, it was concluded that chlorpyrifos exposure for 28 days causes damage to thyroid and suprarenal glands.
\end{abstract}

\section{Introduction}

$\mathrm{O}$ rganophosphates (OP) were first synthesized in Germany before the Second World War. It is widely used in agriculture and public health. It is one of the most commonly used insecticides, accounting for about $50 \%$ of the global insecticidal use (Casida \& Quistad, 2004). This common usage of OP insecticides in public health and agriculture results in an environmental pollution and a number of acute and chronic poisoning events. For this reason, there is a growing public concern about the accumulation of these insecticides in food products and water supplies (Lukaszewicz-Hussain, 2010).

Chlorpyrifos (CPF; 0, 0-diethyl 0-3, 5, 6trichloro-2pyridyl phosphothionate) is a broad spectrum OP insecticide used in the control of a wide variety of insects (Umosen et al., 2012). The oral LD50 of CPF for rats is $135 \mathrm{mg} / \mathrm{kg}$ body weight (Goel et al., 2007). Like other OP, CPF is known to inhibit acethylcholinesterase activity in target tissues (Tripathi and Srivastav, 2010). In addition, it is reported that
CPF may affect different systems, including liver (Khan and Kour, 2007), kidney (Verma et al., 2007), lung (Karaoz et al., 2002), brain (Saulsbury et al., 2009) and erythrocytes (Mansour and Mossa, 2010-a, Demir et al., 2011).

There is increasing evidence that a wide range of chemicals can interfere with thyroid and adrenal functions (De Angelis et al., 2007). Thyroid hormones regulate a number of biological processes essential for growth, metabolism as well as brain maturation (Bernal et al., 2003). Chemicals affecting adrenals can also have serious consequences for the organism, including impaired ability to mount an appropriate physiological response to stress or to maintain electrolyte homeostasis. Moreover, the distinct medullary region releases catecholamines involved in blood pressure and blood flow regulation (De Angelis et al., 2009).

$\mathrm{CPF}$ has been postulated to have multiple effects on the target cells including generation of reactive oxygen species and induction of intracellular 
oxidative stress thereby disrupting normal cellular development and differentiation. Malonadialdehyde (MDA) is a marker of lipid peroxidation resulting from interaction of reactive oxygen species and cellular membrane. The final membrane damage can lead to a loss of cellular homeostasis by changing membrane characteristics (Gultekin et al., 2000).

So, the goal was to study the induced toxicological changes of $\mathrm{CPF}$ in both thyroid and suprarenal glands. Hormonal, serum and tissue oxidative stress biomarker, and histological examinations were recruited in this study.

\section{Materials and Methods}

\section{Animals}

Twenty adult male albino rats weighing about 200-250 grams were obtained from the animal house in Faculty of Science - Minia University. All animals were allowed free access to distilled water and laboratory chow ad libitum food. Every five rats were placed in a separate cage to avoid stress of isolation or overcrowding. They were left freely wandering in their cage for two weeks with 12 hour dark: light cycle for acclimatization before starting the experiment.

Experimental procedures were performed in accordance with the guide of the care and use of laboratory animals approved by the Committee of Minia University: the fewest number of animals estimated to obtain valid results were used and painful procedures were conducted with appropriate sedation to avoid pain and stress.

\section{II- Chlorpyrifos}

Chlorpyrifos technical grade $98 \%$ was obtained from El-Watanya Company, Egypt. It was reconstituted in soya oil to $10 \%$ solution, which was subsequently used for the experiment. Thiobarbituric acid and potassium phosphate buffer used for determination of MDA level were purchased from Sigma and Merck Chemical Companies.

\section{Experimental design}

Rats were randomly classified into the following two groups (10 rats per each):

- Control group (I): each rat received oral soya oil $(2 \mathrm{ml} / \mathrm{kg})$ daily.

- Chlorpyrifos-treated (II) (CPFtreated) group: each rat received $\mathrm{CPF}$ in a dose of $5.4 \mathrm{mg} / \mathrm{kg} /$ day. CPF was administered by gavage once daily for a period of 28 days according to (Uzun et al., 2010).

\section{Biochemical analysis}

At the end of the experimental period, rats were anesthetized by halothane and sacrificed by decapitation. Blood samples were collected from jugular veins and centrifuged for 10 minutes at 5000 round per minute (r.p.m). The obtained clear sera were stored at $-80^{\circ} \mathrm{C}$ until used for:

$$
\text { 1- Serum T3, T4, TSH and }
$$
corticosterone levels were measured by radio-immuno assay using commercial kits (Jeong et al., 2006).

2- Malondialdehyde (MDA) levels in the sera were determined as an indicator of lipid peroxidation by thiobarbituric acid method as previously described by Ohkawa et al., (1979).

\section{V- Oxidative biomarker in thyroid and adrenal tissues}

The thyroid and adrenal glands were dissected and removed free from the surrounding fat and connective tissue. Each thyroid and adrenal glands was longitudinally sectioned, kept at $-80 \quad{ }^{\circ} \mathrm{C}$ and subsequently homogenized in cold potassium phosphate buffer $(0.05 \mathrm{M}, \mathrm{pH} 7.4)$. The ratio of tissue weight to homogenization buffer was $1: 10$. The thyroid and adrenal homogenates were centrifuged at 5000 r.p.m for 10 minutes at $4{ }^{\circ} \mathrm{C}$. The resulting supernatant was used for determination of MDA level according to the method of Ohkawa et al., (1979).

\section{VI- Histological examination}

After rat decapitation thyroid and suprarenal glands tissues were taken. Some pieces were fixed in $10 \%$ neutral buffered formalin (PH 7.2), dehydrated in ascending series of ethanol, cleared in methyl benzoate, embedded in paraffin wax, deparaffinized with xylene and 4-5 $\mu \mathrm{m}$ thick section stained with hematoxylin and eosin for light microscopic examination (Bancroft \& Garble, 2002). Images of some slides were captured using an Olympus computerized microscope in bright-field mode in the Histology Department.

\section{Statistical analysis}

All data were represented as mean \pm standard deviation $(\mathrm{M} \pm \mathrm{SD})$. For comparison between the two means, unpaired student's t- test was used and $\mathrm{P}$ value $\leq 0.05$ was considered to indicate statistical significance.

\section{Results}

T3 showed a significant decrease in CPF-treated group in comparison with control group $(1.48 \pm 0.3$ and $1.1 \pm 0.2 \mathrm{ng} / \mathrm{ml}$ in control and CPF-treated groups respectively) (table 1$)$.

In a similar manner, the level of $\mathrm{T} 4$ in the control group was found to be $45.3 \pm 4.8 \mathrm{ng} / \mathrm{ml}$. In CPFtreated group, there was a significant decrease in the level of T4 $(35.3 \pm 6.4 \mathrm{ng} / \mathrm{ml})$ (table 1$)$.

In contrast to $\mathrm{T} 3$ and $\mathrm{T} 4, \mathrm{TSH}$ showed significant elevation in its level in CPF-treated group in comparison with control group ( $1.5 \pm 0.9$ and $3.55 \pm 0.6$ $\mathrm{ng} / \mathrm{ml}$ in group I and II respectively) (table 1).

Corticosterone level in control group was $22 \pm 3 \mu \mathrm{g} / \mathrm{dl}$ while in CPF-treated group it was increased to $38 \pm 4 \mu \mathrm{g} / \mathrm{dl}$ but these changes was statistically insignificant (table 1).

$\mathrm{CPF}$ significantly increased the lipid peroxides (LPO) level in the serum (table 1), thyroid and adrenal glands (table 2), as evidenced by increased production of MDA as compared to control rats, 
suggesting participation of free radical-induced oxidative cell injury in mediating the toxicity of CPF.

Histological examination of the control group of the thyroid gland showed normal organization of the thyroid follicles with its lumina filled with homogenous colloid and the inter follicular cells lied in between follicles (Fig. 1). Examination of thyroid glands of group II showed decreased amount of colloid as most follicles appeared with empty lumen, exfoliation of the follicular epithelial cells were obvious, and also there were congestion of blood vessels (Fig. 2).

Histological examination of the control group of the adrenal gland showed normal structural organization of the gland with fine vacuolations of zona granulosa cells (Fig. 3). Histological evaluation of adrenal gland of group II showed no major alterations of the microscopic picture in the form of a slight increase in vacuolations of zona granulosa cells (Fig. 4).

Table 1: Effect of CPF administration on different serum measured parameters in adult male albino rats.

\begin{tabular}{|l|c|c|c|c|}
\hline Parameters & & & \\
\hline T3 $(\mathrm{ng} / \mathrm{ml})$ & Control group & CPF-treated group & T-value & P-value \\
\hline $\mathrm{T} 4(\mathrm{ng} / \mathrm{ml})$ & $1.48 \pm 0.3$ & $1.1 \pm 0.2$ & 2.36 & $0.04^{\bullet}$ \\
\hline $\mathrm{TSH}(\mathrm{ng} / \mathrm{ml})$ & $45.3 \pm 4.8$ & $35.3 \pm 6.4$ & 3.25 & $0.01^{\bullet}$ \\
\hline Corticosterone $(\mu \mathrm{g} / \mathrm{dl})$ & $1.5 \pm 0.9$ & $3.55 \pm 0.6$ & 2.82 & $0.02^{\bullet}$ \\
\hline MDA $(\mathrm{nmol} / \mathrm{g}$ protein $)$ & $22 \pm 3$ & $38 \pm 4$ & 1.83 & 0.1 \\
\hline
\end{tabular}

Data represent Mean $\pm S D$ of 10 animals. CPF-treated group: chlorpyrifos-treated group. MDA: malondialdehyde. P: significance. ${ }^{\bullet}$ : significantly different from control group $(P \leq 0.05)$.

Table 2: Effect of CPF administration on the MDA level (nmol/g protein) in the thyroid and adrenal glands of adult male albino rats.

\begin{tabular}{|l|c|c|c|c|}
\hline Organs Group & Control group & CPF-treated group & T-value & P-value \\
\hline Thyroid gland & $1.4 \pm 0.09$ & $2.6 \pm 0.08$ & 4.27 & $0.002^{\bullet}$ \\
\hline Adrenal gland & $2.2 \pm 0.1$ & $4.6 \pm 0.2$ & 2.73 & $0.02^{\bullet}$ \\
\hline
\end{tabular}

Data represent Mean $\pm S D$ of 10 animals. CPF-treated group: chlorpyrifos-treated group. MDA: malondialdehyde. P: significance. •: significantly different from control group $(P \leq 0.05)$.

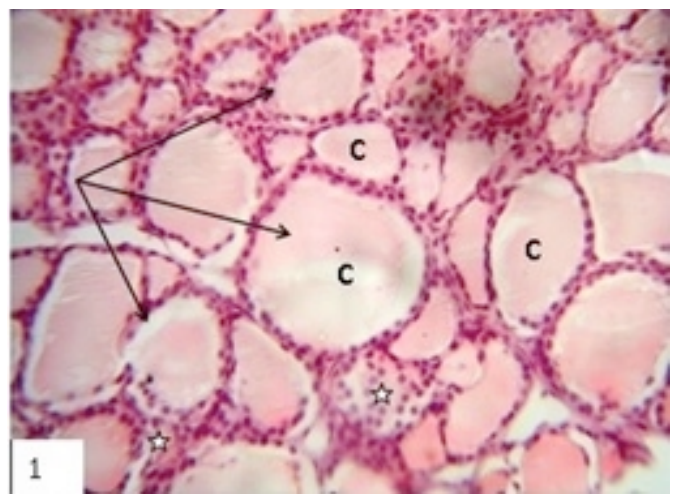

Figure 1: Photomicrograph of the thyroid gland of group I rats showing the normal organization of the thyroid follicles (arrows) with their lumina filled with homogenous colloid $(C)$ and the inter-follicular cells (stars) (H\&E, X400).

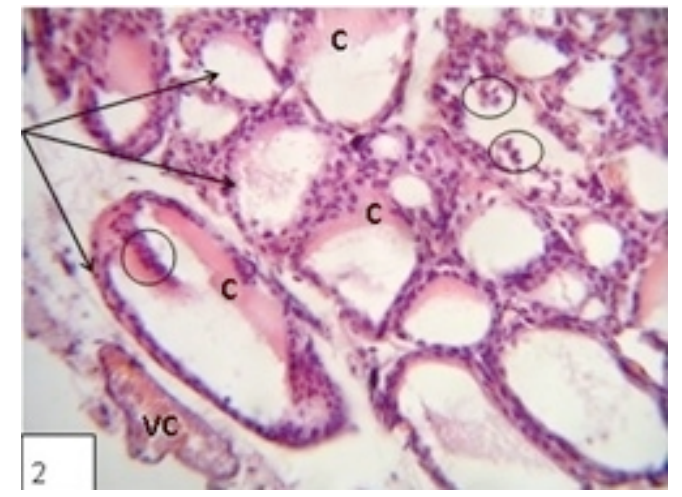

Figure 2: Photomicrograph of the thyroid gland of group II rats showing the degenerated thyroid follicles (arrows). Notice exfoliation of the follicular epithelial cells (circles) in the lumen with decreased its colloid (C) and vascular congestion (VC) (H\&E, X400). 


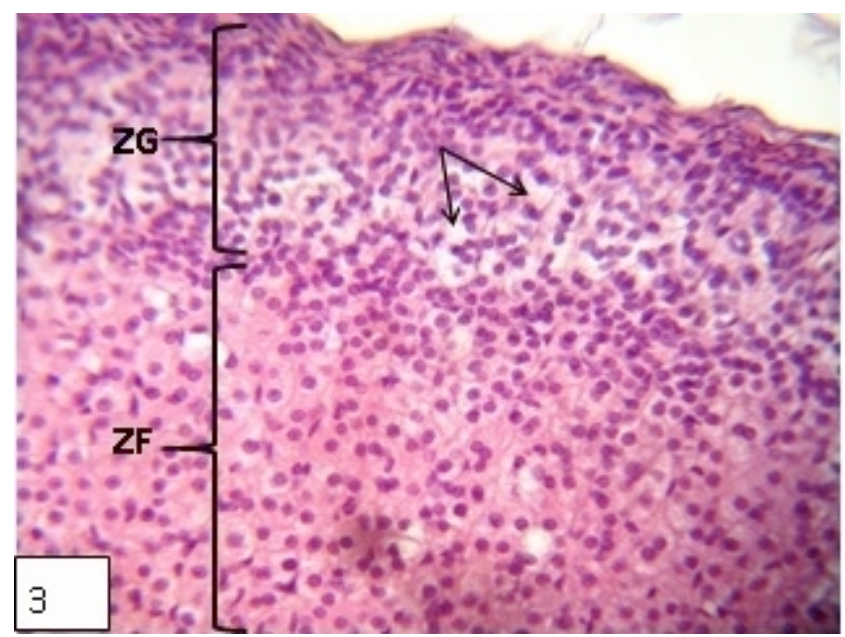

Figure 3: Photomicrograph of the adrenal gland of group I rats showing the normal zona granuloza (ZG) and zona fasiculata (ZF) of the cortex. Notice fine vacuolations of zona granuloza cells (arrow) (H\&E, X400).

\section{Discussion}

Chlorpyrifos (CPF), a broad spectrum organophosphate insecticide, is one of the most extensively used organophosphate insecticides in domestic and industrial applications all over the world (Cetin et al., 2007). Chlorpyrifos (CPF) is classified as a moderately hazardous, Class II insecticide by the WHO (WHO, 1997). So, the aim was to evaluate the alterations in thyroid and suprarenal glands induced by administration of CPF for 28 days in adult male albino rats.

The present study showed that there was statistically significant decrease in the serum T3 and T4 and a significant increase of TSH. This may be attributed to structural damage of CPF to thyroid tissue. This damage results in the decreased T4 level and the decreased $\mathrm{T} 3$ occurs as a consequence to decrease in T4. This is because T3 is formed as peripheral tissue conversion of T4 (Ambali et al., 2011).

These results are similar to that found by Satar et al., (2006) who found a significant decrease in T3 and $\mathrm{T} 4$ and increase in TSH in acute intoxicated rats with OP. This was consistent with the results obtained by De Angelis et al., (2009) upon giving $6 \mathrm{mg} / \mathrm{kg} /$ day of CPF to pregnant rats. Also, this is meeting with Rawlings et al., (1998) who studied CPF in ewes. However, Jeong et al., (2006) found similar results in male rats while insignificant changes in female rats were reported. Jeong and his coworkers did not give explanation for this sex difference but it may be attributed to physiological changes of pregnancy as these female rats received the toxin during pregnancy.

That result is in contrast to Ambali et al., (2011) who found that there was insignificant decrease in T3 and T4 on giving CPF in association with lead. This may be attributed to the lower dose of CPF given to rats $(4.25 \mathrm{mg} / \mathrm{kg} /$ day $)$.

Also, Havilland et al., (2010) found that there was significant increase in $\mathrm{T} 4$ in serum of female rats in contrast to male rats which had no significant changes. It is worth to mention that these rats exposed

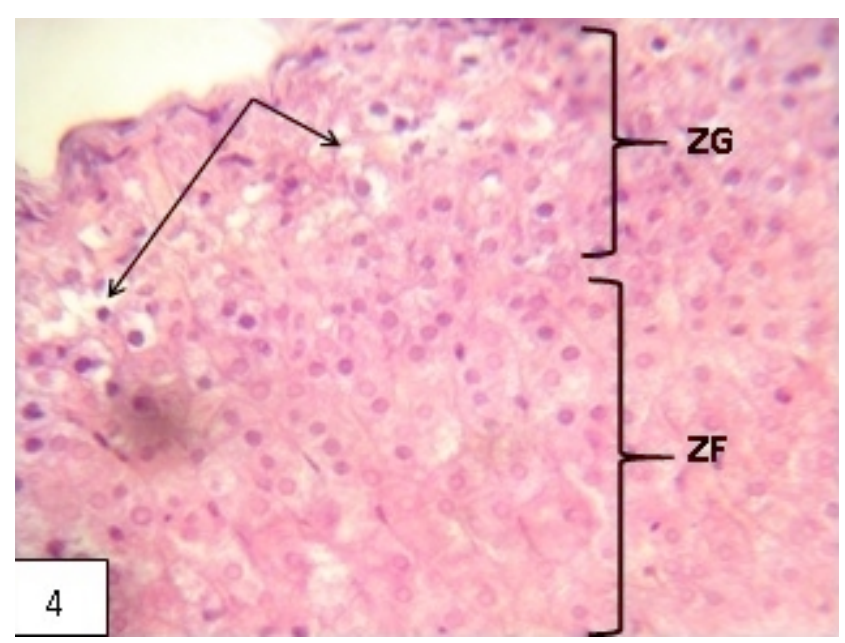

Figure 4: Photomicrograph of the adrenal gland of group II rats showing a slightly increased vacuolations (arrows) of zona granuloza (ZG) cells of the cortex (H\&E, X400).

in utero only to CPF for 3 days and thyroid hormones were tested 150 days postnatal.

In a human study done by Lacasana et al., (2010) in the association between organophosphate pesticides exposure and thyroid hormones in floriculture workers, they found that there were significant increase in TSH and T4 and decrease in T3 with increase metabolites of OP in urine.

A thyreostatic effect of $\mathrm{CPF}$ was suggested also by a study conducted on men of reproductive age with fertility problems, showing an inverse association between urinary concentration of CPF metabolites and T4 level and a positive association with TSH (Meeker et al., 2006).

The significant increase in TSH concentration in CPF-treated group may be attributed to the compensatory mechanism of the body to stimulate the thyroid gland to secrete more T4. This is in agreement with Ambali et al., (2011).

This study showed that there is insignificant increase in corticosterone level. This is consistent with Jeong et al., (2006) but in contrast to Rawlings et al., (1998). Otherwise, there is a scarcity of literature studying the effect of CPF on adrenal hormonal level.

As regard the oxidative stress effect of CPF, this study revealed that there was a significant increase in the serum and tissue MDA concentration in thyroid and adrenal glandular tissues. This result reflects the oxidative damage of CPF in thyroid and adrenal glands in spite of serum levels may reflect oxidative effect on other tissues beside thyroid and adrenal effect. This damage to thyroid tissue was accompanied by decreased thyroid hormone levels. This is in agreement with Ambali et al., (2010-a), Mansour and Mossa (2010-b) and Gultekin et al., (2000).

Tuzmen et al., (2007), Ambali et al., (2010-b) and Ambali et al., (2012) have shown similar increase in lipoperoxidative damage to the brain following $\mathrm{CPF}$ exposure in rats. Also, other studies showed elevated MDA in different tissues of rats exposed to CPF as in 
liver and kidney $\{$ (Mansour and Mossa, 2011) and (Aly et al., 2010) $\}$, in testis and pituitary $\{$ (Shittu et al., 2012) and (Umosen et al., 2012) $\}$, in haematology (El Sharkawy et al., 2013), in retina (Ahmed et al., 2010), and in lung (Uzun et al., 2010).

As regard histological examination of the studied organs, the results went in the same line as hormonal changes. The significant decrease in T3 \&T4 is supported by thyroid histological changes where degenerated thyroid follicles with decreased its colloid, exfoliation of the follicular epithelial cells and vascular congestion. Similar results have been obtained in other studies conducted in experimental models as De Angelis et al., (2009) where rats were exposed to CPF in dose 3 and $6 \mathrm{mg} / \mathrm{kg} /$ day for 3 days.

Jeong et al., (2006) reported histopathological damage in the form of vacuolation or necrosis of thyroid follicular epithelial cells in male rats exposed during pregnancy (in utero) and for 13 weeks after birth to 10 and $100 \mathrm{mg} / \mathrm{kg}$ dose levels of CPF-methyl. Adrenal glands also showed vacuolations of zona granulosa cells. This was consistent with the present results.

On the contrary, another study by Jacobsen et al., (2004) in which rats received 5 types of OP compounds one of them was CPF $(0.3 \mathrm{mg} / \mathrm{kg} / \mathrm{day})$ for 28 days showed mild degree of follicular cell hypertrophy with no suprarenal gland changes.

In conclusion, the present study has shown the ability of CPF to induce oxidative and histological alterations to the thyroid and adrenal glands. Such damage is responsible for hormonal changes induced by exposure to CPF. CPF- induced changes in the thyroid was more severe than that in adrenals.

\section{Recommendations}

More regulations regarding the use of CPF as a pesticide both domestic and agricultural.

\section{Acknowledgement}

Many thanks are given to Dr. Neveen Makram Azeez, Lecturer of Physiology, Faculty of Medicine, Minia University for the help she offered in this work in evaluation of MDA level.

\section{References}

Ahmed, N., Mohamed, S. and Abdel-Wahhab, A. (2010): Chlorpyrifos-induced oxidative stress and histological changes in retinas and kidney in rats: Protective role of ascorbic acid and alpha tocopherol. Pesticide Biochemistry and Physiology, 98(1): 33-38.

Aly, N., EL-Gendy, K., Mahmoud, F. and El-Sebaeb, K. (2010): Protective effect of vitamin C against chlorpyrifos oxidative stress in male mice. Pesticide Biochemistry and Physiology, 97(1): 7-12.

Ambali, S., Akanbi, D., Shittu, M., Giwa, A., Oladipo, O. and Ayo, O. (2010-a): ChlorpyrifosInduced Clinical, Hematological and Biochemical Changes in Swiss Albino Mice-
Mitigating effect by co-administration of vitamins C and E. Life Science Journal, 7(3): 37-44.

Ambali, S.F., Idris, S., Onukak, C., Shittu, M., and Ayo, O. (2010-b): Ameliorative effect of vitamins $\mathrm{C}$ on short-term sensorimotor and cognitive changes induced by acute chlorpyrifos exposure in Wistar rats. Toxicology and Industrial Health, 26(9): 547558.

Ambali, S.F., Makinde, O., Shittu, M., Adeniyi, S. and Mowuogwu, F. (2012): Alleviating Effect of Phyllanthus niruri on Sensorimotor and Cognitive Changes Induced by Subacute Chlorpyrifos Exposure in Wistar Rats. American Journal of Medicine and Medical Sciences, 2(3): 50-58.

Ambali, S.F., Orieji, C., Abubakar, W.O., Shitti, M. and Kawu, M.U. (2011): Ameliorative Effect of vitamin $\mathrm{C}$ on alterations in thyroid hormones concentrations induced by subchronic coadministration of Chlorpyrifos and Lead in Wistar rats. Journal of Thyroid Research, volume 2011, article ID 214924, 6 pages.

Bancroft, J. and Garble, M. (2002): Theory and Practice of Histological Techniques. 5th edition, Churchill Livingstone: Harcourt, PP. 85-98, 310-314.

Bernal, J., Guardano-Ferraz, A. and Morte, B. (2003): Perspectives in the study of thyroid hormone action on brain development and function. Thyroid, 13: 1005-1012.

Casida, E. and Quistad, B. (2004): Organophosphate toxicology: safety aspects of nonacetylcholinesterase secondary targets. Chemical Research in Toxicology, 17: 983998.

Cetin, N., Cetin, E., Eraslan, G. and Bilgili, A. (2007): Chlorpyrifos induces cardiac dysfunction in rabbits. Res. Vet. Sci., 82: 405-408.

De Angelis, S., Pricci, F., and Franzellin, F. (2007): Effects of environmental chemicals on thyroid function. In The Endocrine Disruptors by Marino, M. and Mita, D. (Eds.). Transworld Research Network, Trivandrum, Kerala, India, PP. 53-66.

De Angelis, S, Tassinari, R., Maranghi, F., Eusepi, A., Di Virgilio, A., Chiarotti, F., Ricceri, L., Venerosi-Pesciolini, A., Gilardi, E., Moracci, G., Calamandrei, G., Olivieri, A. and Mantovani, A. (2009): Developmental exposure to chlorpyrifos induces alterations in thyroid and thyroid hormone levels without other toxicity signs in CD-1 mice. Toxicological Sciences, 108 (2): 311-319.

Demir, F., Uzun, G., Durak, D. and Kalender, Y. (2011): Subacute chlorpyrifos-induced oxidative stress in rat erythrocytes and the protective effects of catechin and quercetin. Pesticide and Biochemical Physiology, 99(1): 77-81. 
Elsharkawy, E., Yahia, D. and El-Nisr, N.A. (2013): Sub-chronic exposure to chlorpyrifos induces hematological, metabolic disorders and oxidative stress in rat: Attenuation by glutathione. Environmental Toxicology and Pharmacology, 35(2): 218-227.

Goel, A., Dani, V. and Dhawan, D. (2007): Zinc mediates normalization of hepatic drug metabolizing enzymes in chlorpyrifos-induced toxicity. Toxicology Letters, 169(1): 26-33.

Gultekin, F., Ozturk, M. and Akdogan, M. (2000): The effect of organophosphate insecticide chlorpyrifos-ethyl on lipid peroxidation and antioxidant enzymes (in-vitro). Archives of Toxicology, 74(9): 533-538.

Haviland, A., Butz, D. and Porter, W. (2010): Longterm sex selective hormonal and behaviour alterations in mice exposed to low doses of chlorpyrifos in utero. Reproductive Toxicology, 29 (1): 74-79.

Jacobsena, H., Østergaardb, G., Lama, H., Poulsen, M.E., Frandsen, H., Ladefoged, O. and Meyer, O. (2004): Repeated dose 28-day oral toxicity study in Wistar rats with a mixture of five pesticides often found as residues in food: alphacypermethrin, bromopropylate, carbendazim, chlorpyrifos and mancozeb. Food and Chemical Toxicology, 42(8): 12691277.

Jeong, S., Kim, B., Kang, H., Ku, H.O. and Cho, J.H. (2006): Effect of chlorpyrifos-methyl on steroid and thyroid hormones in rat F0- and F1-generations. Toxicology, 220(2-3): 189202.

Karaoz, F., Gultekin, F., Akdogan, M., Oncu, M. and Gokcimen, A. (2002): Protective role of melatonin and a combination of vitamin $\mathrm{C}$ and vitamin $\mathrm{E}$ on lung toxicity induced by chlorpyrifos-ethyl in rats. Experimental and Toxicologic Pathology, 54 (2): 97-108.

Khan, S. and Kour, G. (2007): Subacute oral toxicity of chlorpyrifos and protective effect of green tea extract. Pesticide and Biochemical Physiology, 89(2): 118-123.

Lacasana, M., López-Flores, I., Rodríguez-Barranco, M., Aguilar-Garduño, C., Blanco-Muñoz, J., Pérez-Méndez, O., Gamboa, R., Bassol, S. and Cebrian, M.E. (2010): Association between organophosphate pesticides exposure and thyroid hormones in floriculture workers. Toxicology and Applied Pharmacology, 243(1): 19-26.

Lukaszewicz-Hussain, A. (2010): Role of oxidative stress in organophosphate insecticide toxicity - Short review. Pesticide Biochemistry and Physiology, 98 (2): 145-150.

Mansour, S. and Mossa, A. (2010-a): Adverse effects of lactational exposure chlorpyrifos in suckling rats. Human \& Experimental Toxicology, 29 (2): 77-92.

Mansour, S. and Mossa, A. (2010-b): Oxidative damage, biochemical and histopathological alterations in rats exposed to chlorpyrifos and the antioxidant role of zinc. Pesticide Biochemistry and Physiology, 96(1): 14-23.

Mansour, S. and Mossa, A. (2011): Adverse effects of exposure to low doses of chlorpyrifos in lactating rats. Toxicology and Industrial Health, 27(3): 213-224.

Meeker, D., Ryan, L., Barr, B. and Hauser, R. (2006): Exposure to nonpersistent insecticides and male reproductive hormones. Epidemiology, 17(1): 61-68.

Okhawa, H., Ohishi, N. and Yagi, K. (1979): Assay for lipid peroxides in animal tissues by thiobarbituric acid reaction. Analytical Biochemistry, 95(2): 351-358.

Rawlings, C., Cook, J. and Waldbillig, D. (1998): Effects of the pesticides carbofuran, chlorpyrifos, dimethoate, lindane, triallate, trifluralin, 2, 4-D, and pentachlorophenol on the metabolic endocrine and reproductive endocrine system in ewes. Journal of Toxicology and Environmental Health - Part A, 54(1): 21-36.

Satar, S., Satar, D., Kirim, S. and Leventerler, H. (2006): Effects of acute organophosphate poisoning on thyroid hormones in rats. Toxicology Letters, 64S (1): 254.

Saulsbury, D., Heyliger, O., Wang, K. and Johnson, J. (2009): Chlopyrifos induces oxidative stress in oligodendrocyte progenitor cells. Toxicology, 259(1-2): 1-9.

Shittu, M., Ayo, J., Ambali, S., Fatihu, M.Y., Onyeanusi, B.I. and Kawu, M.U. (2012): Chronic chlorpyrifos-induced oxidative changes in the testes and pituitary gland of Wistar rats: Ameliorative effect of vitamin C. Pesticide Biochemistry and Physiology, 102(1): 79-85.

Tripathi, S. and Srivastav, A. (2010): Liver profile of rats after long-term ingestion of different doses of chlorpyrifos. Pesticide Biochemistry and Physiology, 97(1): 60-65.

Tüzmen, N., Candan, N. and Kaya, E. (2007): The evaluation of altered antioxidative defense mechanism and acetylcholinesterase activity in rat brain exposed to chlorpyrifos, deltamethrin, and their combination. Toxicology Mechanisms and Methods, 17(9): 535-540.

Umosen, A., Ambali, S., Ayo, J., Mohammed, B. and Uchendua C. (2012): Alleviating effects of melatonin on oxidative changes in the testes and pituitary glands evoked by subacute chlorpyrifos administration in Wistar rats. Asian Pacific Journal of Tropical Biomedicine, 2(8): 645-650.

Uzun, G., Demir, F., Kalender, S., Bas, H. and Kalende, R.Y. (2010): Protective effect of catechin and quercetin on chlorpyrifosinduced lung toxicity in male rats. Food and Chemical Toxicology, 48(6): 1714-1720.

Verma, R., Mehta, A. and Srivastava, N. (2007): In vivo chlorpyrifos oxidative stress: attenuation 
by antioxidant vitamins. Pesticide and Biochemical Physiology, 88(2): 191-196.

WHO (1997): The WHO recommended classification

of pesticides by hazard 1996-1997.
International Programme on chemical safety, WHO/IPCS/96.3.

\section{الملخص العربي}

\section{التأثيرات السمية الناتجة عن إعطاء الكلوربيريفوسي علبي الغدد الدرقية و الكظرية في ذكور البريبر

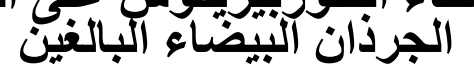

\section{ميلاد جاد بولس و جكلين فكري زاهر و عصام محمود حافظ1 و نشوه فتحي الطحاوي2}

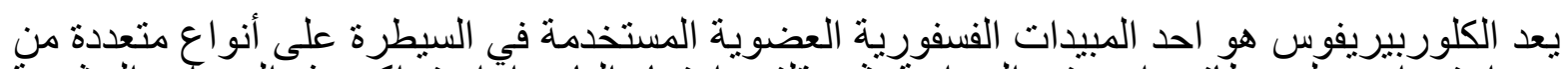

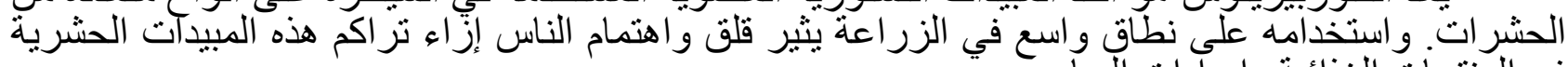

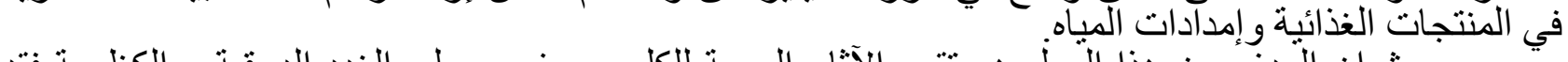

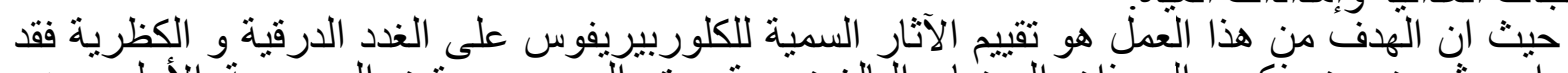

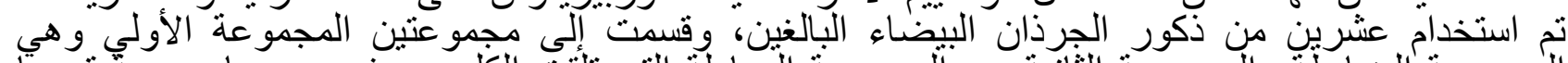

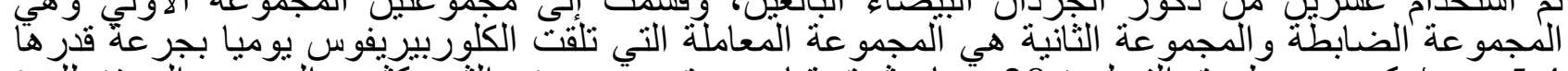

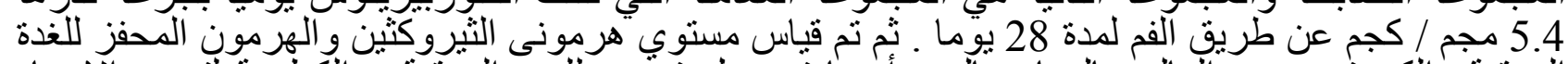

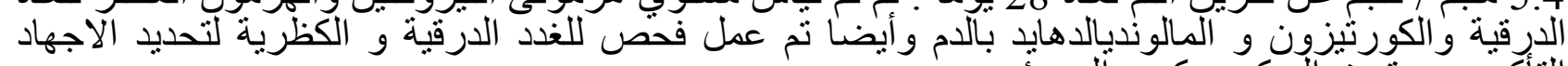

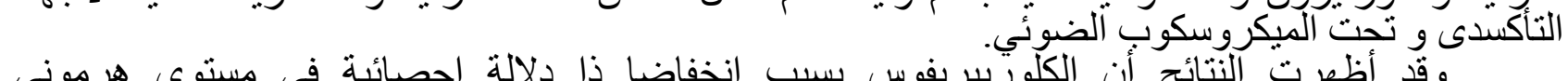

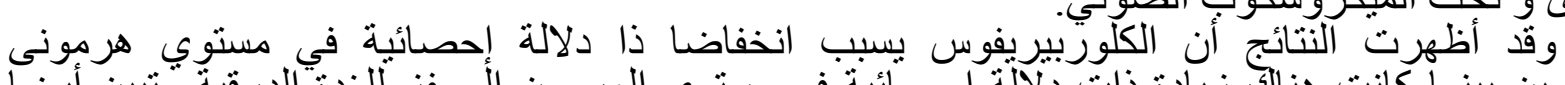

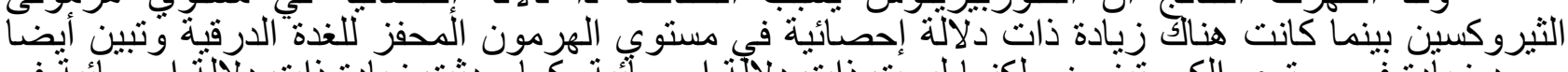

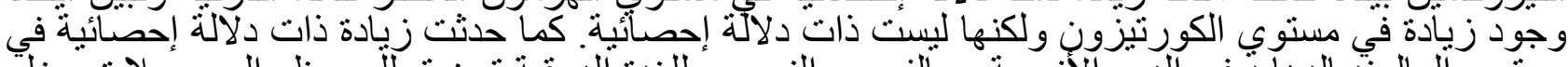

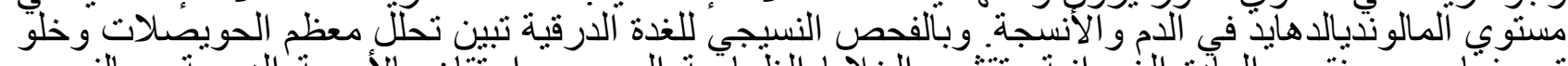

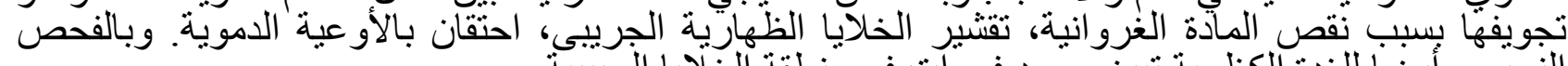

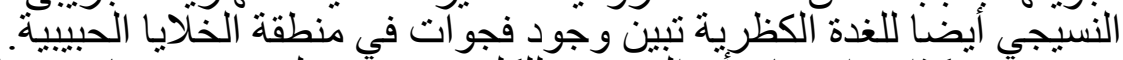

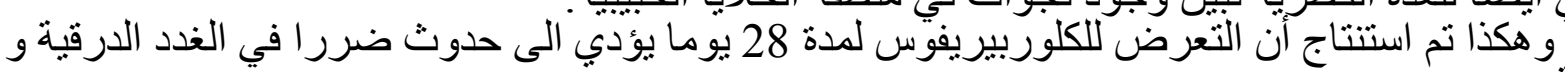
الكظرية.

\footnotetext{
1 قسم الطب الثرعي و السموم الإكلينيكية كلية الطب جامعة المنيا

2 قسم الهستولوجي لية كلية الطب جامعة المنيا
} 